Bu makaleye atıfta bulunmak için/To cite this article:

ULUTAŞ, M. (2021). Teknoloji Yönetimi: Almanya, Japonya ve Türkiye Karşılaştırılması. Atatürk Üniversitesi Sosyal Bilimler Enstitüsü Dergisi, 25 (4), 1609-1625.

\title{
Teknoloji Yönetimi: Almanya, Japonya ve Türkiye Karşılaştırılması
}

Mehmet ULUTAŞ (*)

Öz: Araştırma karşılaştırmalı olarak, Almanya, Japonya ve Türkiye’nin eğitim sistemlerinde teknolojiye yapılan yatırımlarıla teknolojiyi kullanmadaki durumlarını ortaya koymak ve konu ile ilgili mevcut durumlarını irdelemeyi amaçlamaktadır. Araştırmada nicel araştırma yöntemlerinden belge tarama modeli kullanılmıştır. Araştırmanın çalışma grubunu Almanya, Japonya ve Türkiye ülkeleri oluşturmaktadır. Ülkelerle ilgili veriler, OECD, STAT, TUIK ve WIPO istatistiklerinden alınmıştır. Çalışma bu verilerle sınırlıdır. Verilerin çözümlenmesinde, istatistiksel olarak sayısal değerlere, yüzdeliklere bakılmıştır. İlgili değerler belirtilen ülkeler arasında karşılaş̧tırlmıştır. Türkiye'nin diğer gelişmiş ülkelere göre uzaktan eğitim ve bilgisayar destekli eğitim gibi teknolojinin etkilerinin üst düzeyde olduğu eğitim uygulamalarında gerilerde olduğu, Ar-Ge harcamaları ele alındı̆ğnda Almanya ve Japonya'nın harcama tutarları Türkiye'ye oranla oldukça yüksek olduğu gibi sonuçlara ulaşılmış ve Türkiye'de eğitimin, teknolojiyle iç içe entegre edilerek, mevcut sorunların giderilmesine çalışllması, bilim ve teknolojiye gerekli önemin verilmesi gibi önerilerde bulunulmuştur.

Anahtar Kelimeler: Karşılaştırmalı eğitim, teknoloji, eğitim yönetimi, teknoloji yönetimi.

\section{Technology Management: Germany, Japan and Turkey Comparison}

Abstract: Research comparatively, Germany, Japan and Turkey's education system in the use of technology to reveal the status of investments made in technology and aims to analyze the current situation regarding the topic. Document scanning model, one of the quantitative research methods, was used in the research. Working group of the Research in Germany, Japan and Turkey constitute the country. Country-related data are taken from OECD, STAT, TUIK and WIPO statistics. The study is limited to these data. In the analysis of the data, statistically numerical values and percentages were examined. Relevant values are compared between the countries mentioned. Turkey's compared to other developed countries, distance education and computer is in the back of the upper level is the educational practices of the effects of technology aided education, $R \& D$ expenses discussed when it reached the conclusion that, quite high compared to Turkey amounting to spend Germany and Japan, and Turkey 'Also, suggestions were made such as integrating education with technology, trying to overcome the existing problems and giving the necessary importance to science and technology.

\footnotetext{
${ }^{*}$ Dr. Öğr. Üyesi, Aydın Adnan Menderes Üniversitesi Eğitim Fakültesi Eğitim Bilimleri Bölümü (e-posta: mehmet.ulutas@adu.edu.tr) (D) ORCID ID. https://orcid.org/0000-0002-6539-2039

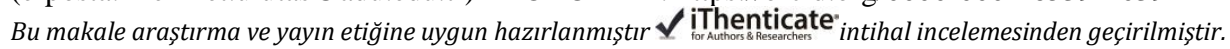


Keywords: Comparative education, technology, educational administration, technology management.

Makale Geliş Tarihi: 27.02.2021

Makale Kabul Tarihi: 20.12.2021

DOI: 10.53487/ataunisosbil.887939

\section{Giriş}

Yaşadığımız dünya, sınırların ortadan kalktığı, bilginin kolay ulaşılabilir hale geldiği, küresel paylaşımların hat safhalara ulaştığı bir dünya haline gelmiştir. Bunun en önemli etkenleri bilginin hızlı gelişimi ve paylaşılabilmesidir. İlgili gelişim kaynaklarından belki de en önemli koşut ise teknolojidir. Günümüz dünyasında artık her alanda, her yaştan bireylerin kullanımına sunulan bu eşsiz değer, vazgeçilmez ve yadsınamaz bir olgu haline gelmiştir.

Teknolojinin, sistemlerin yaşamını devam ettirmedeki yeri tartışılamayacak derecede önemlidir. Teknolojiyi elinde tutan toplumların diğer toplumlara bir üstünlük sağladığını yaşamımızın her alanında görmekteyiz. Bu algılar sahip olduğumuz her nesnede kendini göstermektedir. Teknolojiye sahip olmanın sağladığı bu üstünlük ayrıca kültürün aktarılmasında ve diğer toplumlarca benimsenmesinde de önemli rol oynamaktadır. Teknolojiye sahip olan ve bu konuda başarılı olan ülkeler neredeyse tüm dünya tarafından tanınmakta ve gıptayla bakılmaktadır. Tüm olumlu istatistiklerin sahibi olan bu ülkeler, gelişmiş medeniyetler seviyesine ulaşmışlardır. Bu ülkelerin başını çeken Japonya ve Almanya ülkelerinin ismini tanımayan, teknolojilerine neredeyse sahip olmayan bir toplum yoktur. Bu ülkeler otomotivden beyaz eşyaya, sanayiden okullara, iş hayatından sosyal yaşama dek örnek alınacak ülkeler olarak bilinmektedirler.

Sistem yaklaşımıyla bakılacak olursa, teknoloji tüm örgütlerin önemli bir girdisidir. Teknolojinin kullanım örnekleri ya da yararlanma şekilleri örgütün verimliliğini arttıracak önemli koşulları meydana getirmektedir. Özellikle bir toplumun temellerinin atıldı̆̆ eğitim kurumlarında teknolojinin etkili kullanımı artık bir gereklilik halini almiştır.

Tüm dünyanın 2019 yılında tanıştı̆̆ı, Türkiye'nin de 2020 mart ayında ciddi bir şekilde hissettiği Koronavirüs Salgını (COVID-19), yaşattıkları ve hissettirdikleriyle insanlığa, bilimle teknolojinin ne denli önemli olduğunu acı bir şekilde göstermiştir. Salgın koşullarında da teknolojik yatırımlar ve bunların yönetimi bir kez daha önemini tüm dünyaya göstermiştir. Eğitimlerin uzaktan eğitimle yürütülmesi, internet bağlantı hızları, öğrencilerin sahip olduğu teknolojik araçlar gibi konular daha önemli hale gelmiştir. Teknoloji günümüzde, eğitim için var olması gereken önemli bir etken haline dönüşmüştür. Ülkelerin de sosyo-ekonomik gelişmişlik seviyeleri, sahip oldukları teknolojik altyapılar, eğitim teknolojilerine yapılan yatırımlar ve teknolojinin yönetimi gibi konuların ne denli önemli olduğu bir kez daha görülmektedir.

Hızla gelişen dünyaya ayak uydurması gereken örgütlerin başında eğitim örgütleri gelmektedir. Eğitim örgütlerinin, bağlı bulunduğu toplumun gelişimini sağlayıcı etkisi göz ardı edilememektedir. Eğitim örgütlerinin varlıklarını devam ettirebilmeleri ve çağa 
uygun yönetilmesinin önemi, bu misyonu gerçekleştirmek için çok önemlidir. Dolayısıyla yönetim süreçlerinin işlerliğinde bu faktörler dikkatlerden çıkarılmamalıdır. Teknoloji kullanımının ve bunun için sağlanan kaynakların eğitim kurumlarına olan etkisi incelenmesi gereken faktörlerdir. Gelişimi sağlayan ve ivme kazandıran bu faktörlerden nasıl yararlanılmaktadır? Araştırmada bu soruya yanıtlar aranmaya çalışılmıştır.

Eğitim sistemlerinde farklı işlevsel yöntemlere karşılaştırmalı olarak bakmak gerekmektedir. Dünyada yapılan uygulamaları görmek, bunları araştırmak ve tartışmak elbette en iyiyi sentezleyebilmek için önemli bir uğraşıdır. Bu çerçeveden bakılacak olursa karşılaştırmalı eğitim araştırmamızın temelini oluşturmaktadır. Çalışmada ele alınan teknolojinin kullanımı ile ilgili karşılaştırmalı bir bakış açısı, literatürde eksikliği hissedilmiş bir alandır. Karşılaştırmalı eğitim çalışmalarının da yeni yeni önem kazandığı günümüz dünyasına bu araştırmayla da bir katkı sağlanmak istenmiş̧ir.

İlgili çalışmada karşılaştırmalı eğitim perspektifi, eğitim yönetimi çerçevesinden sunulmaya çalışılmıştır. Almanya, Japonya ve Türkiye'de bu konu ile ilgili çalışmalar ne durumdadır? İlgili etkenler, kaynak kullanımları ve uygulamalar araştırılarak literatüre bilimsel bir katkı sağlanıp, mevcut bir boşluk da bu şekilde doldurulmaya çalışılmıştır.

\section{A. Problem Durumu}

Teknolojinin yıllar içerisindeki gelişimi, insanlık olarak yeni bir eksene girmemizi sağlamıştır. Ancak bu durum tüm insanlık için maalesef geçerli değildir. Bazı toplumlar bu üretimi sağlarken, bazıları sadece ayak uydurmak durumunda kalmaktadır. Hatta bazı toplumlar bu takibi bile yapamamaktadırlar. Toplumların gelişmişlik düzeyleri sadece bu ayrımla bile gözlemlenebilir.

Toplumlarda eğitimin önemi ve yeri nasıl tartışılamazsa günümüz dünyasında sürekli bir gelişme içerisinde olan teknolojinin yeri de artık tartışılmaz hale gelmiştir. Özellikle sanayi devrimiyle beraber her geçen gün önemini arttırmış 20 yy'in ortalarından itibaren ise hemen hemen her alanın vazgeçilmez bir olgusu haline gelmiştir. Teknolojinin her alanda etkisi olduğu gibi eğitim sektöründe de yeri ve önemi yadsınamayacak derecededir.

Örgütsel kültürün temel öğelerinin analizinde teknoloji, gerçekçilik ve verimlilik başarılı örgütlerin en önemli özellikleri olarak belirtilmekle birlikte, bu örgütlerin sahip oldukları örgütsel kültür de başarının odak noktasını oluşturmaktadır. Örgütlerin başarısı için tabi ki sadece teknolojik öğelere bağlı olmadığı, aynı zamanda insan faktörünün de bu başarıda önemli yer teşkil ettiği unutulmamalıdır (Çelik, 2012). Günümüzde eğitimin özellikle gelişmiş ülkelerde klasik eğitim anlayışından çıkmış ve köklü bir dönüşümle karşı karşıya kaldığı söylenebilir. Bu dönüşümün temelinde ise teknolojinin kullanımı olduğunu söylemek yanlış olmayacaktır.

Teknoloji, eğitim sistemlerinin günümüzdeki gerekli en önemli girdilerinden biridir. Dolayısıyla bu gerekliliği iyi bir şekilde okul sistemlerine entegre eden ülkelerin başarıya ulaşmada bir adım önde olduğu söylenebilir. Eğitimde teknoloji kullanımının bilgiye 
ulaşım ve elde edilen bilgilerinin paylaşımı konusunda büyük kolaylıklar sağladığı şüphe götürmez bir gerçektir. Teknoloji eğitimin kitlelere ulaşabilmesini sağlayan, mesafeleri bir problem olarak görmeyen yegâne araçtır. Alan çalışmamızdaki ülkelerden birisi olmasa da Çin'in uzaya göndermiş olduğu bir uzay mekiğinin içerisindeki öğretmenin dünyadaki kendi okulunun öğrencileriyle sembolik de olsa bir ders işlemesi bunun en iyi kanitidir.

Eğitim yönetiminde teknolojinin yeri çok önemli olsa da gerektiği kadar irdelenmemektedir. Ancak günümüzün bu çok önemli gücünün yönetim birimlerinde de incelenmesi artık bir gereklilik halini almaktadır. Kurumların ve bireylerin kendilerini çağın şartlarına uygun yetiştirmeleri gerekmektedir. Eğitim yöneticilerinden de istenilen yetkinliklerden birisi de teknolojiyle barışık olmalarıdır.

Örgütsel etkililik birey ve grup etkinliğini içerse de bunlardan daha ötededir. Bu durum üç boyut açısından etkililiğin dayandığı faktörlere göre değişir. Bu faktörler; örgütün tipi, yaptığı iş ve kullanılan teknolojidir (Karslı, 2004, s. 138). Teknolojisiyle etkili olmak isteyen bir kurumda kullanılan teknolojinin de önemi yadsınamayacaktır.

Araştırmamızda ele alınan Almanya'ya bakılacak olursa, ülkenin eyaletlerden oluştuğu görülmektedir. Günümüz Almanya'sında on altı eyalet bulunmaktadır. Eyaletlerin eğitim uygulamaları birbirinden farklı olmakla beraber her eyaletin kültür bağımsızlığı vardır. Buna bağlı olarak, her Eyalet Parlamentosu ve Hükümeti, kendi eyaletlerinin okul ve kültürel alanlarındaki işlerinden sorumludurlar. Bu yüzden Almanya'da tek bir okul örgütü mevcut değildir (Aytaç’tan aktaran Ersoy, 1998, s. 7).

14 ayrı eğitim modelinin uygulandığı Almanya'da eğitimde standartlar getirilmeye çalışılmışsa da eğitim sisteminde birtakım eksiklikler bulunmaktadır. PISA 2000, PISAE ve PISA 2003 adı verilen uluslararası araştırmalarda Almanya eğitiminin 31 ülke arasında 21. olması Almanya'da şok etkisi yaratmış ve 16 eyaletin bakanları 2001 yılında eğitimde alınması gereken önlemleri ortaya koymuşlardır. Bu önlemler şunlardır (Krapp'tan aktaran Kantos, 2011, s. 51):

- Okul öncesi eğitimde dil becerisinin geliştirilmesi için alınacak önlemler,

- İlkokulda okuma becerisinin iyileştirilmesi ve geliştirilmesi için alınacak önlemler,

- Göçmen öğrencilerin uyumu için alınacak önlemler,

- Eğitim standartları ve sonuçlara bağlı değerlendirmeyle okullarda kaliteli eğitime yönelik önlemler,

- Öğretmenlerin yöntem ve vizyon konusundaki becerilerini ve yeteneklerini iyileştirmeye yönelik önlemler,

- Okul ve okul dışı tam günlük aktivitelerinin geliştirilmesine ve öğrencilerin teşvik edilmesine yönelik önlemler.

Almanya'da ortaokullarda ICT (Information, Communication and Technology-Bilgi, İletişim ve Teknoloji) öğrenme için sadece bir araç olarak değil, aynı zamanda ayrı bir ders olarak da verilmektedir. Birçok Alman eyaletinde ICT müfredatı yazılım programı kullanmayı, arama motoru ve ağ üzerinden iletişimi ve program geliştirme kabiliyetini gerektirmektedir. Avrupa'da Almanya'nın da içerisinde bulunduğu bazı ülkelerde okullarda bilgisayarlaşma oranı en az 20 öğrenciye bir bilgisayar düşecek şekildedir. Alman okullarındaki bilgisayarların \%10’u öğretmenlerin kullanımına verilmektedir. Bu 
oran Avrupa standartların oldukça altındadır. Bilgisayarlar, etkili iletişim ve iş birliğinde öğretmenlerin kullandıkları bir araç haline gelmiştir. İş birliği ve değişimi teşvik etmek için bilgisayarların kullanılması bir zorunluluk halini almıştır. Bu yaklaşım Almanya'da benimsenen önemli bir olguya dönüşmüştür. Avrupa'da uygulama projeleri bilgisayar ağları ile karakterize edilmiştir. Uygulama projelerinde bilgisayar teknolojilerini kullanma gereksinimleri; iş birliği için öğretmen yetenekleri, okullarda Bilgi İletişim Teknolojileri (BİT) kullanımı olarak belirtilmiştir. Bilgisayar okur-yazarlığı öğretmen eğitimine daha ciddi ve kalıcı şekilde entegre edilmektedir (Gräsel, 2007).

Almanya'da teknolojinin erkek egemenliğini belirten bir çalışmada, çeşitli programlar ve ulusal öğrenme koşulları tartışılmış ve özellikle cinsiyet eşitliğini sağlayıcı bir takım teknoloji eğitimi önerilerde bulunulmuştur. Araştırmada 6-12 yaş çocukları için Avusturya, Estonya, Finlandiya, Fransa ve Almanya'dan oluşan 5 Avrupa ülkesinde programlar ve teknoloji eğitiminin sistemi üzerinde güçlü ve zayıf yönlerin keşfedildiği belirtilmiştir. (Rasinen, Virtanen, Endepohls-Ulpe, Ikonen, Ebach ve Stahlvon Zabern, 2009). Teknolojinin kullanım boyutlarının ne denli detaylarda araştırıldığ dünyaya örnek teşkil etmektedir.

Araştırmanın bir diğer ülkesi olan Japonya topraklarının \%84'ü tarıma elverişsiz olması, sık sık depremlerin yaşanması, doğal kaynaklarının kısıtlı olması, temel maddelerde dışa bağımlı olması ve kıyılarda her sonbahar kasırgalar yaşanması dikkat çekmekle birlikte, önde giden insan gücü ile özellikle son 30 yıl yaşanılan ekonomik gelişmelere engel olamamıştır. Ekonomik gelişmelere paralel olarak yüksek düzeyde bir yaşam standardına sahip bir ilke durumundadır. (Erdoğan, 2003; Memmedova Telci, 2011).

Kültürel olarak Japonlar uygulama ve uyarlamayı çok iyi bilen toplumdur. Çăgdaş bir ülkedir. Kendine özgü ve uluslarına bağlı bir millettir (Güvenç, 2002). Japonlar gelişmiş ekonomi ve teknolojinin yanında, oldukça gelişmiş bir eğitim sistemine sahiptir. Japonya bugün dünyada zorunlu öğretim ile ortaöğretimde en yüksek okullaşma oranına ulaşan ülkelerden birisidir (Erdoğan, 2003, s. 107).

Japon ekonomisindeki büyüme 1960'lar itibariyle gerçek olarak \%11'lere ulaşmıştır. Bu oran 1960-1972 dönemi için Almanya'da \%4,6, ABD'de ise \%4,3'tür. Günümüzde Japonya'nın ekonomik büyümesinin ardında yatan unsurlar sanayinin hızlı büyümesi, teknolojiye verilen önem, yüksek düzeyde eğitim ile bol bulunan iş gücünün piyasalara atılması olmuştur (ISEI, 1989).

Japonya bugün oldukça gelişmiş bir eğitim sistemine sahiptir. Japonya'da ulusal bütçenin \%12'si eğitime ayrılırken \%7,7'si askeri harcamalara ayrılmaktadır. ABD'nin askeri harcamalara ilk ve ortaöğretim için yaptığ 1 harcamalardan yedi katını veriyor olduğu göz önünde bulundurulursa Japonya'nın eğitim sisteminde kaynak açısından ne kadar rahat olduğu dikkatlerden kaçmamaktadır (Erdoğan, 2003, s. 117).

İkinci Dünya Savaşının ağır yenilgisinden sonra gözlenen "Japon Mucize” sinde eğitimin bir kaldıraç rolü oynadığına gerek Japonlar gerekse Japonya’yı inceleyen araştırmacılar hemfikirdir. Japonlar eğitimi diğer ekonomik, sosyal ve idari sistemlerden ayrı düşünmemeleri; kültürü, yani insanın doğaya kattı̆̆ı her şeyi tüm bu sistemlerin temeline koydukları gözlenmektedir (Akarsu, 1999). Japonya eğitim alanında dünyada oldukça başarılı bir konumda bulunmaktadır. Ekonomik gelişmede olduğu gibi PISA 
sınavı gibi uluslararası sınavlarda gösterdiği üstün başarı ile de dikkat çekmektedir. Bu nedenle Japonya'nın eğitim sistemini daha iyi anlayabilmek için eğitime etki eden bütün faktörleri göz önüne alarak Japon temel eğitim sistemi, yönetimi, öğretmen yetiştirme sistemi ve finansmanını incelemek gerekmektedir. Japonya, 9 yıllık mecburi eğitim süresince öğrencilere hem bilimsel hem kültürel hem de sanatsal alanda yüksek kalitede bir eğitim sunmaktadır. Japonya özellikle bazı konularda büyük başarı sağlamıştır (Bakioğlu ve Altay Gökmen, 2013).

Japonya'da teknoloji yüksekokulları (kolejleri) bulunmaktadır. Teknoloji yüksekokullarının amacı özel disiplinlerde derinlemesine öğrenme gerçekleştirmek amacıyla bir öğrencinin istihdam için gerekli yeteneklerini geliştirmektir (Bakioğlu ve Altay Gökmen, 2013, s. 275). Ayrıca her bölgede (prefecture) en az bir eğitim araştırma enstitüsü bulunur. Kentlerde ve kasabalarda ise daha küçük çaplı olan araştırma kurumları mevcuttur. Bütün bu enstitülerin üstünde Ulusal Araştırma Enstitüleri Federasyonu bulunmaktadır. Bu enstitülerin temel işlevi eğitim konusunda araştırmalar yapmak ve öneriler sunmaktır (Kazuo'dan aktaran Erdoğan, 2003).

Japonya'da eğitim uygulamalarıyla eğitim araştırmaları arasındaki ilişki eğitim teknolojilerinin ilk konuşulduğu zamanlardan itibaren konuşulmaya ve tartışılmaya başlanmıştır. Eğitim araştırmaları ve uygulamaları daha çok eğitim teknolojileriyle bağlantılı olduğu görülmektedir (Nakayama ve Ueno, 2008). Japonya eğitim sistemi teknolojiyle iç içe bir haldedir denilebilir.

Çalışmamızda Almanya ve Japonya örneklerinin seçilmesi bu iki ülkenin 20. yy'deki savaşlardan mağlup olarak ayrılmaları ve buna rağmen teknolojik olarak dünyanın en iyi teknoloji üreten ve pazarlayan ülkeleri arasında olmalarıdır. Bu bağlamda, Almanya'nın Avrupa'nın merkezi ülkelerinden biri konumunda olması ve batıyı simgelemesi, Japonya'nın da doğu ülkelerinin kültürünü yansıtması, iki ülkenin de bu farklı kültürleri simgeleyen teknolojinin merkezindeki ülkeler olması, çalışmada incelemeye alınmasındaki en önemli ölçütlerdir. Bunların yanında, bu iki ülkenin PISA sınavlarındaki başarıları ve eğitime verdikleri önemi de tercih edilmelerini açıklamaktadır.

PISA sınavlarında ülkeler, almış oldukları puanlarla eğitim adına çok şey ifade etmektedir. Türkiye, PISA 2018 sinav sonuçlarıyla 2015 sınavlarına göre daha başarılı almıştır. PISA 2015 araştırmasına 72 ülke, PISA 2018 araştırmasına ise 79 ülke katılmıştır. PISA 2015 araştırmasında okuma becerilerinde 50. sırada yer alan Türkiye, PISA 2018 araştırmasında 40. sıraya yükselmiştir. PISA 2015 araştırmasında matematik okuryazarlığında 50. sırada yer alan Türkiye, PISA 2018 araştırmasında 42. sıraya yükselirken PISA 2015 araştırmasında fen okuryazarlığında 54. sırada yer alan Türkiye, PISA 2018 araştırmasında 39. sıraya yükselmiştir. Ancak bu sonuçlara OECD ülke karşılaştırmalarıyla bakıldığında çok bir fark yoktur. PISA 2018 sınav sonuçlarına göre; okuma becerilerinde Almanya 20., Japonya ise 15. olurken, matematik okuryazarlığında Almanya 20., Japonya 6. olmuş son olarak fen okuryazarlı̆̆ında ise Almanya 16., Japonya 5. sıradadır ("PISA 2018 Türkiye Ön Raporu", 2019).

Almanya ve Japonya ile birlikte Türkiye'nin durumuna da bakılarak yapılacak karşılaştırma, eğitim sistemlerinin geliştirilmesi hususunda büyük önem arz edeceği düşünülmektedir. Karşılaştırmalı araştırmaların eğitim sistemlerin gelişmelerinde önemli bir yeri olduğu ve bu gibi çalışmaların sayısının da özellikle kendine özgü 
alanlarda yetersiz olduğu düşünülecek olursa, yapılacak araştırma ile mevcut literatüre bu anlamda bir katkı sağlamak, çalışmanın önemini oluşturmaktadır.

\section{B. Araştırmanın Amacı}

Araştırma karşılaştırmalı olarak, Almanya, Japonya ve Türkiye'nin eğitim sistemlerinde teknolojiyi kullanmadaki durumlarını ortaya koymak ve konu ile ilgili mevcut durumlarını irdelemeyi amaçlamaktadır. Bu amaç dâhilinde ülkelerin; GSYIH (Gayrisafi Yurtiçi Hâsıla) oranları, Ar-Ge (Araştırma ve Geliştirme) harcamaları, PISA (The Programme for International Student Assessment) sonuçları, patent başvuru sayıları, bilgi ve iletişim teknoloji harcamasının GSYIH Oranı sonuçları ve internet erişim oranları irdelenmiştir.

\section{Yöntem}

Araştırma, Almanya, Japonya ve Türkiye ülkelerinde eğitim sistemlerinde teknolojiyi kullanmaları arasındaki farklılıkların çözümlemesini yapmayı amaçladığından tarama modeli ile yapılandırılmıştır. Araştırmada nicel araştırma yöntemlerinden belge tarama modeli kullanılmıştır. Tarama (survey) çalışmaları, belli bir grubun birtakım özelliklerini belirlemek için veri toplamayı amaçlayan bir araştırma yöntemidir (Büyüköztürk, Kılıç Çakmak, Akgün, Karadeniz ve Demirel, 2019).

Araştırmanın çalışma grubunu Almanya, Japonya ve Türkiye ülkeleri oluşturmaktadır. Ülkelerle ilgili veriler, OECD (The Organisation for Economic Cooperation and Development), STAT (Statistics Japan), GTAI (Germany Trade \& Invest), TUIK (Türkiye İstatistik Kurumu) ve WIPO (World Intellectual Property Organization) istatistiklerinden alınmıştır. Çalışma bu verilerle sınırlıdır. Verilerin çözümlenmesinde, istatistiksel olarak sayısal değerlere, oranlara ve yüzdeliklere bakılmış, bu değerler Türkiye verileri ile karşılaştırılmıştır.

\section{Bulgular ve Yorum}

Bu bölümde, ilgili ülkelerin GSYİH oranları, Ar-Ge harcamaları, PISA sınav sonuçları, eğitime yapılan yatırımlar, patent başvuru sayıları, bilgi ve iletişim teknoloji harcamasının GSYIHH oranı ve internet erişim oranları karşılaştırılmalı şekilde tablolarla sunulmaktadır.

\section{A. GSYIH Oranları}

Tablo 1'de GSYİH oranları bakımından araştırmada ele alınan ülkelerin karşılaştırılması yer almaktadır. Bir ülkenin büyüme performansının başarısı, o ülkenin gelişmiş ülkelerle arasındaki kişi başına gelir farkını ne ölçüde azaltabildiği ile ölçülür ("Bilişim Sanayicileri Derneği Raporu", 2012, s. 30). Bu sonuçlar, teknolojiyi odak noktasına almada birtakım fikirler vermektedir. 
Tablo 1: 2020 Yılı GSYIH Oranları

\begin{tabular}{lcc}
\hline & Ülkeler & Kişi Başına Düşen GSYİH (\$) \\
\hline Almanya & 54457 \\
Japonya & 41502 \\
Türkiye & 28455 \\
\hline
\end{tabular}

Kaynak: OECD, 2020.

Tablo 1'de görülen sayılar dikkate alındığında en yüksek kişi başına düşen GSYIH Almanya'dadır. Almanya'yı 41502 Dolarla Japonya takip etmektedir. Dikkat çeken sonuç ise Türkiye'nin bu oranının iki ülkeye göre oldukça düşük olmasıdır. $\mathrm{Bu}$ sonuçların teknoloji kullanımını aynı oranda etkileyeceğini düşünmek yanlış olmayacaktır.

\section{B. Ar-Ge Harcamaları}

Teknoloji ile yakından ilgili bir konu ise araştırma ve geliştirme faaliyetleridir. Gelişimi odaklayan ülkelerin de bu faaliyetleri odak noktalarına almaları yadsınamaz bir gerçektir. Aşağıda yer alan Tablo 2 ve Tablo 3 ’te, ülkelerin bu harcama tutarları ile ilgili harcamaların GSMH'ye oranı verilmektedir. Şekil 1'de de ülkelerin oranları grafik ile verilmeye çalışılmıştır.

Tablo 2: Ar-Ge Harcamaları

\begin{tabular}{cc}
\hline Ülkeler & Harcama Tutarı \\
\hline Almanya & 70 Milyar Euro (466 Milyar TL) \\
Japonya & 18.43 Trilyon Yen (1.018 Trilyon TL) \\
Türkiye & 5528 Milyon TL \\
\hline
\end{tabular}

Kaynak: GTAI, 2019; STAT, 2016; TUIK, 2014.

Tablo 2'de Almanya, Japonya ve Türkiye'nin Ar-Ge harcamaları verilmektedir. Sonuçlara bakıldığında Japonya'nın Ar-Ge harcamaları (1.018 Trilyon TL) oldukça iyi durumdadır. Almanya sonuçlarına bakıldığında (466 Milyar TL) Japonya'nın yarısı kadar bir harcama tutarı dikkat çekmektedir. Ancak en çok dikkat çeken miktar Türkiye'nin Ar-Ge harcamalarıdır (5528 Milyon TL). Sonuçlar arasında büyük bir fark bulunmaktadır. Japonya'nın teknolojik üstünlüğü bu sonuçla desteklenebilir. Bu tutarlar ışı̆̆ında teknolojiye yapılan yatırımların, gelişme ve kalkınma yatırımlarının Türkiye'de diğer ülkelere oranla daha düşük olacağı tahmin edilebilir durumdadır. 
Tablo 3: Ar-Ge (R\&D) Harcamalarının GSYIH Oranı

\begin{tabular}{cccc}
\hline Ülkeler & 2000 & Oranlar \\
& 2,401 & 2,714 & 2017 \\
\hline Almanya & 2,906 & 3,137 & 3,213 \\
Japonya & 0,468 & 0,799 & 0,961 \\
Türkiye & 2,118 & 2,282 & 2,372 \\
OECD & & \\
\hline
\end{tabular}

Kaynak: OECD, 2020.

Tablo 3'te 2000, 2010 ve 2017 y1llarında Ar-Ge harcamalarının GSYIH'ye oranı görülmektedir. OECD ülkelerinin ortalamasının 2.118'den 2.372'e çıktığı görülürken, Almanya'da bu oranlar 2.401 'den 3,038'e yükselmiştir. Japonya ise 3,213'le önemli bir oranla dikkat çekmektedir. Ancak Türkiye'de bu rakamların çok düşük olduğu önemli bir bulgudur. Türkiye'de oranların \%1'in altında olduğu görülmektedir. Teknolojiye kalkınmaya verilen önem bu oranlardan anlaşılabilir. Almanya ve Japonya'nın özellikle teknolojide dünya liderleri olmalarının altında yatan yatırımlardan biri de bu oranlar gösterilebilir. Şekil 1'de ise ilgili ülke sonuçlarının diğer OECD ülkeleri arasındaki yerini göstermektedir. Şekilde görüldüğü üzere Türkiye oldukça gerilerdedir.

Şekil 1: Ar-Ge (R\&D) Harcamalarının GSYİH Oranı

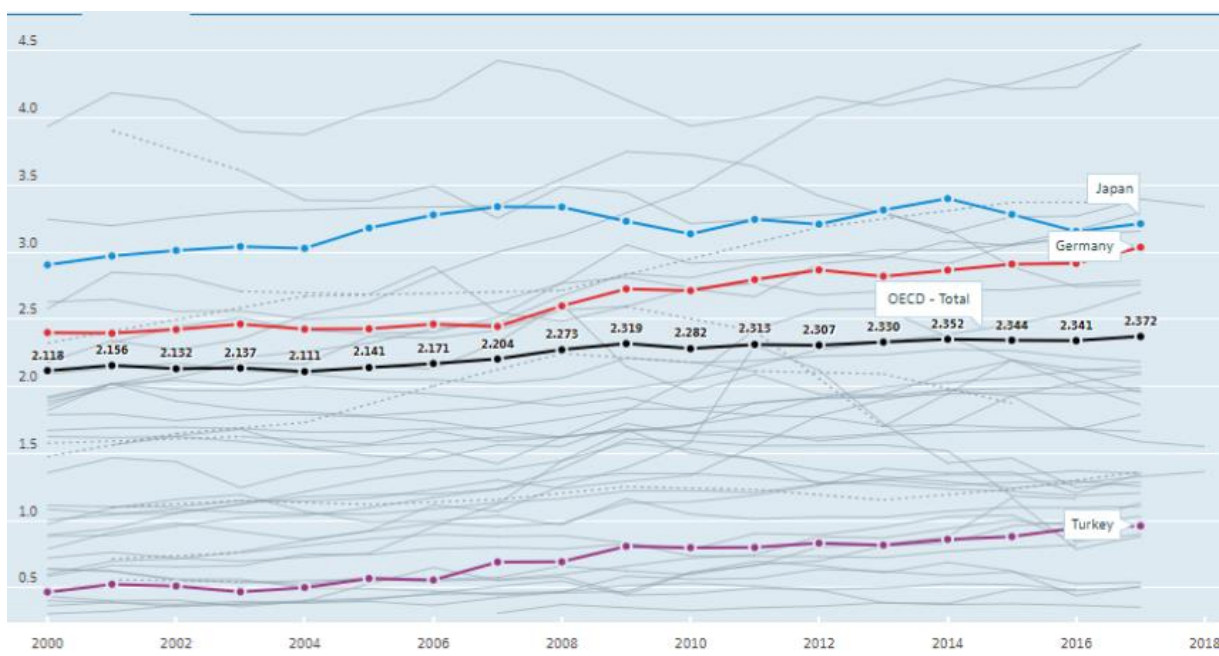

Kaynak: OECD, 2020

Şekil 1'e bakıldığında Ar-Ge harcamalarının GSYİH'ye oranlarının çizgi grafikleri gösterilmektedir. Grafiklerde Almanya'nın giderek artan bir görüntüsü varken, Japonya'nın en yüksek oranlara sahip olduğu dikkat çekmektedir. Bir başka dikkat çeken husus ise Türkiye'nin sahip olduğu oranların çok gerilerde olduğudur. Almanya ve 
Japonya OECD ortalamalarının üzerinde değerlere sahipken Türkiye OECD ortalamasının oldukça altındadır.

\section{PISA Sonuçları}

Almanya, Japonya ve Türkiye'nin PISA 2015 ve 2018'de almış olduğu Matematik, Okuma ve Fen alanlarındaki sonuçlar OECD ortalamaları ile kıyaslandığında aşağıdaki şekilde bir tablo ortaya çıkmaktadır. Tablo 4'te üç temel alana ilişkin ortalama puanlar görülmektedir. Bu puanlar ışığında Almanya ve Japonya'nın OECD ortalamalarının üzerinde olduğu görülürken, Türkiye'nin ise ortalamaların altında olduğu gözlemlenmektedir.

Tablo 4: 2015 ve 2018 Y1lı PISA Puanları

\begin{tabular}{|c|c|c|c|c|c|c|c|c|c|}
\hline & \multicolumn{2}{|c|}{ Matematik } & \multirow{2}{*}{$\begin{array}{l}2018 \\
\text { Sira }\end{array}$} & \multicolumn{2}{|r|}{ Okuma } & \multirow{2}{*}{$\begin{array}{l}2018 \\
\text { Sira }\end{array}$} & \multicolumn{2}{|c|}{ Fen } & \multirow{2}{*}{$\begin{array}{l}2018 \\
\text { Sira }\end{array}$} \\
\hline & 2015 & 2018 & & 2015 & 2018 & & 2015 & 2018 & \\
\hline $\begin{array}{l}\text { Alman } \\
\text { ya }\end{array}$ & 498 & 496 & 20 & 499 & 486 & 20 & 514 & 502 & 16 \\
\hline $\begin{array}{l}\text { Japony } \\
\text { a }\end{array}$ & 525 & 522 & 6 & 509 & 493 & 15 & 545 & 531 & 5 \\
\hline Türkiye & 418 & 451 & 42 & 414 & 453 & 40 & 422 & 465 & 39 \\
\hline $\begin{array}{r}\text { OECD } \\
\text { Ortalamas1 }\end{array}$ & 486 & 487 & - & 479 & 472 & - & 495 & 488 & - \\
\hline
\end{tabular}

Kaynak: OECD, 2020.

Özellikle teknoloji ile etkili olabilecek matematik ve fen sonuçlarının Türkiye'de ortalamalara göre daha düşük olduğu dikkat çekmektedir. Türkiye puan ortalamalarını yükseltip OECD ortalamalarına yaklaşmakla beraber Almanya, Japonya ve OECD puanlarının altında dereceler almıştır. Sıralamalara bakıldığında da Japonya'nın ilk sıralarda olması dikkat çekmektedir. Türkiye ise sıralamalarda her iki ülkenin de oldukça gerisinde görülmektedir.

\section{Eğitime Yapılan Yatırımlar}

Eğitime yapılan yatırımlar öğrenci başına harcanan dolar miktarı üzerinden karşılaştırılmıştır. OECD verilerine göre irdelenmiş sonuçlar Tablo 5'te sunulmaktadır. 
Tablo 5: Öğrenci Başına Yapılan Harcamalar (2015-2016 veya son bildirimler Dolar Bazında)

\begin{tabular}{cc}
\hline Ülkeler & Harcama Miktarı (Dolar) \\
\hline Almanya & 17.036 \\
Japonya & 19.289 \\
Türkiye & 8.901 \\
\hline
\end{tabular}

Kaynak: OECD, 2020.

Tablo 5'te, ülkelerin ilköğretim ve ortaöğretimde öğrenci başına yapılan harcamalar aktarılmaktadır. Harcama tutarlarına bakıldığında Almanya ve Japonya'da harcamaların birbirine yakın olduğu gözlemlenmektedir. Türkiye'nin yapmış olduğu harcama miktarlarının bu iki ülkeye oranla düşük olduğu dikkatlerden kaçmamaktadır.

\section{E. Patent Sayıları}

Araştırmaya dahil edilen ülkelerin patent sayıları ve harcama miktarları WIPO (World Intellectual Property Organization [Dünya Fikri Mülkiyet Örgütü]) istatistikleriyle Tablo 6'da sunulmaktadır. Patent sayıları bir toplumun gelişmişlik düzeyini de yansıtmaktadır. Patentler bilime ve düşünceye katkı olarak da düşünülebilir. Üretimi destekleyen en önemli göstergelerden biri olarak görülebilir. Bu nedenle teknolojiye katkısı da önemsenmelidir. Patent sayıları teknoloji kullanımını doğrudan etkileyen bir unsur olarak düşünülebilir.

Tablo 6: 2018 Yılı Ülkelerin Patent Sayıları ve Harcama Miktarları

\begin{tabular}{ccc}
\hline Ülkeler & Patent Sayıları & $\begin{array}{c}\text { Harcama (GSYH- } \\
\text { Dolar) }\end{array}$ \\
\hline Almanya & 180,086 & $3,811.31$ \\
Japonya & 460,369 & $4,971.77$ \\
Türkiye & 9,360 & $2,081.58$ \\
\hline
\end{tabular}

Kaynak: WIPO, 2020

Tablo 6'da araştırma ülkelerinin patent sayıları ve patentler için gayrisafi yurtiçi harcamadan ayrılar tutar dolar olarak sunulmaktadır. Patent sayıları ile gelişmişlik düzeyi arasında doğru bir orantının olduğunu söylemek yanlış olmayacaktır. Patent sayısı aynı zamanda yeni üretilen ürünleri yansıtmaktadır. Tabloda Japonya'nın patent 
sayılarının $(460,369)$ diğer ülkelere göre bir hayli fazla olduğu görülürken, Türkiye'nin patent sayısının ise $(9,360)$ oldukça düşük olması dikkat çekicidir. Bunun için harcanan miktarlar arasındaki fark da dikkat çekici olan bir diğer unsurdur.

Tablo 7'de ise ülkelerin toplam patent başvuruları yer almaktadır. İlgili başvurular dört yıllık aralarla verilmeye çalışılmıştır. Patent başvuruları yurtiçi, yurtdışı olmak üzere toplam sayı üzerinden verilmiştir.

Tablo 7: Ülkelerin Toplam Patent Başvuruları

\begin{tabular}{cccc}
\hline Ülkeler & 2010 & 2014 & 2018 \\
\hline Almanya & 185854 & 197313 & 201367 \\
Japonya & 522955 & 526001 & 520306 \\
Türkiye & 4387 & 6826 & 9670 \\
\hline
\end{tabular}

Kaynak: WIPO, 2020

Tablo 7'de ise üç ülkenin toplam patent başvuruları bir tabloda toplanmaya çalışılmıştır. Sayılar arasındaki fark oldukça dikkat çekicidir. Japonya diğer ülkelere kıyasla oldukça ileride görülmektedir. Türkiye ise iki ülkenin sayılarından oldukça gerilerde yer almaktadır.

\section{F. Evlerde Var Olan Bilgisayar Oranları}

OECD verileri arasında teknoloji kullanımı için önemli bir değişken olabilecek evlerde var olan bilgisayar oranları Tablo 8'de verilmektedir. Verilen bu oranlar 2013, 2015 ve 2017 yılları şeklinde üç farklı şeklide sunulmaktadır.

Tablo 8: Evde Bilgisayara Sahip Olma Oranları

\begin{tabular}{cccc}
\hline Ülkeler & 2013 & 2015 & 2017 \\
\hline Almanya & 88,9 & 91 & 92,9 \\
Japonya & 81,7 & 79,8 & 72,5 \\
Türkiye & 49,8 & 50,6 & 50 \\
\hline
\end{tabular}

Kaynak: OECD, 2020.

Tablo 8'de Almanya, Japonya ve Türkiye'ye ait, teknolojiyle yakında ilgili olabilecek evlerde bilgisayara sahip olma oranları yer almaktadır. Almanya'nın yükselen ve iyi bir oranı olduğunu söylemek yanlış olmayacaktır. Japonya'da ise düşen bir oran dikkat çekmektedir. Türkiye'nin oranları ise iki ülkeye göre düşük görülmektedir. Oranlar ise $\% 50$ civarındadır. 


\section{G. İnternet Erişim Oranları}

Aşağıda yer alan Tablo 9'da ise bir başka teknolojik unsur olarak sayllabilecek ülkelerin internet erişim oranları yıl bazında verilmektedir. Verilen oranlar teknolojinin kullanım noktasında önemli bilgiler sunmaktadır. İnterneti kullanabilme oranları günümüzde teknolojinin kullanılmasında ilk araç konumundadır.

Tablo 9: İnternet Erişim Oranları

\begin{tabular}{cccc}
\hline Ülkeler & 2009 & 2015 & 2019 \\
\hline Almanya & 79,1 & 90,3 & 94,8 \\
Japonya & 67,1 & - & - \\
Türkiye & 30 & 69,5 & 88,3 \\
\hline
\end{tabular}

Kaynak: OECD, 2020.

Tablo 9'da ülkelerin hane internet erişim oranları verilmektedir. Oranlar 2009, 2015 ve 2019 yıl bazında OECD istatistiklerinden alınmıştır. Değerlere bakıldığında Almanya'nın bahsedilen üç yılda da oranları bulunmaktadır. Ayrıca 2009 yılından sonra gelişim göstererek 69,1 oranı 2019 yılında 94,8 gibi yüksek bir oran çıkmıştır. 2009 yılı oranlarına göre Almanya'dan biraz daha az bir değere sahip olan Japonya'nın diğer yıllara ilişkin verileri beyan edilmemiştir. 2009 yılı oranlarına göre oldukça düşük bir orana sahip olan Türkiye'nin, 2015 ve 2019 yıllarında kademeli olarak büyümüş, oldukça iyi bir orana ulaşmıştır $(\% 88,3)$.

\section{Sonuç, Tartış̧a ve Öneriler}

Araştırmanın bulgularına dayanılarak oluşturulan sonuçlar ve sonuçlar dahilinde yapılan öneriler aşağıda yer almaktadır. Sonuçlar tartışmalarla birlikte verilmeye çalışılmışken öneriler ise madde madde verilmeye çalışılııştır. Genel bir değerlendirme ile Türkiye'nin diğer ülkelerden teknoloji kullanımı ve yönetiminde daha gerilerde olduğu söylenebilir.

\section{A. Sonuç ve Tartışma}

Kişi başına düzen GSYİH sonuçlarına göre Almanya en yüksek orana sahiptir. Japonya'nın değeri Almanya'ya yakınken Türkiye'nin değeri iki ülkeye oranla oldukça düşüktür. Bu değerler teknoloji kullanımını ve yönetimini etkileyebilecek bir değişken olarak dikkat çekmektedir. Uşun (2009) da Türkiye'nin diğer gelişmiş ülkelere göre uzaktan eğitim ve bilgisayar destekli eğitim gibi teknolojinin etkilerinin üst düzeyde olduğu eğitim uygulamalarında gerilerde olduğu sonucuna varmıştır. Bundan dolayı Türkiye'de bilgi ve iletişim teknolojilerinden yeni yollar aramanın gerekli olduğunu vurgulamıştır. $\mathrm{Bu}$ ifadeler araştırmanın bulgularıyla benzer bir yerlere vurgu yapmaktadır. 
Ar-Ge harcamaları ele alındığında Almanya ve Japonya'nın harcama tutarları Türkiye'ye oranla oldukça yüksektir. Japonya'nın dünyanın teknoloji merkezi olarak algılanmasındaki yegâne sebeplerden biri olması bu bulguya dayandırılabilir. Ayrıca ArGe harcamalarının GSYİH oranına bakıldığında Türkiye'nin ciddi bir biçimde geride olduğu görülmektedir. Bu bulgular da teknolojinin ülke içindeki üretimini ve kullanımını etkileyebilecek önemli bir göstergedir. Çetindamar, Can ve Pala (2006)’ya göre teknoloji yönetiminde Ar-Ge faaliyetlerinin ve patent-lisans çalışmalarının önemi belirtilmiş ve bunların teknolojinin korunmasında süreğen hale getirilmesinde önemli değişkenler olduğu belirtilmiştir. Bu ifadeler çalışmanın bulgularını destekler ifadelerdir.

PISA Sınav sonuçlarına bakıldığında diğer sonuçlara benzer şekilde Türkiye puanlarının daha düşük olduğu görülmektedir. Ayrıca özellikle teknolojiyle ilgili olabilecek matematik ve bilim sonuçlarının daha da düşük olduğu gözlemlenebilir. Bu bulgular bizlere teknoloji için önemli olan alanlara yönelik eğitim eksikliklerimiz olduğunu ifade etmektedir. İnan ve Bekler (2014)'e göre PISA sınav sonuçlarına önemli düzeyde etki edebilecek unsurlar arasında ülkenin kişi başına düşen geliri, ebeveynlerin eğitim düzeyi, sınıf ortamı gibi değişkenler de gösterilmektedir. Bu bulgular da teknolojik gelişimlere etki edebilecek önemli değişkenler olarak gösterilebilir.

Öğrenci başına yapılan harcamalara bakıldığında ise Türkiye'nin diğer ülkelere göre yarı yarıya daha az bir yatırım yaptığı görülmektedir. Bu yatırımın yine ülke gelişimiyle doğru orantılı olduğu dikkatlerden kaçmamalıdır. Cural, Pekkaya ve Oral (2016) da yaptıkları araştırmada finansman ile ilgili politikaların oluşturulması üzerinde durmuşlardır. Bu uygulamada kamusal maliyetlerinde yanında bireysel maliyetlerin de dikkate alınması vurgulanmıştır. Bireysel maliyetlerin azaltılmasına yönelik eğitim olanaklarının artırılması, aile gelirlerinin dikkate alınması, beslenme, ulaşım, kitap vb. yardımcı unsurların işe koşulması gibi önerilerde bulunmuşlardır. Bu ve benzeri öneriler araştırmanın sonuçlarını destekler niteliktedir.

Teknolojik olarak önemli olan patent başvuru sayıları ise bir başka durumu gözler önüne sermektedir. Türkiye'nin başvuru sayıları Diğer iki ülkeye göre oldukça düşüktür. $\mathrm{Bu}$ veriler de teknolojiyle doğrudan ilgilidir. Teknolojinin ekonomiyle de önemli bir ilişkisi olduğu düşünülebilir. Kırankabeş ve Erçakar (2012)'a göre de patent başvuruları ve ekonomik büyüme arasında pozitif yönde anlamlı bir ilişki bulunmuştur.

Evde bilgisayara sahip olma göstergeleri de teknolojinin kullanımıyla doğrudan ilgilidir. $\mathrm{Bu}$ bulgulara bakıldığında Türkiye'nin oldukça geride olduğu görülebilmektedir. Bu bulgu ekonomik olarak satın alma gücüyle de ilgilidir. Özellikle salgın sürecinde öğrencilerin sahip olduğu teknolojik cihazlar ön plana çıkmaktadır. Günümüz çağında öğrencilerin bilgisayar, tablet gibi eğitimlerine destek olacak teknolojilere sahip olması önemli bir unsur olarak görülmektedir.

İnternet erişim oranlarına bakıldığında en iyi oranın Almanya'da olduğu söylenebilir. Teknolojinin kullanımı yansıtan bu sonuçlara bakıldığında Türkiye'nin oranlarının önemli bir artışa geçtiği sonucudur. EBA (Eğitim Bilişim Ağı) 'da yaşanan bağlantı sorunları da benzer bir nedene bağlıdır. Bununla alakalı medyada da çıkan haberler bulunmaktadır. İnternet erişim bantlarının ülke geneli artırılması önemli bir gereklilik halini almaktadir. 


\section{B. Öneriler}

1. Türkiye büyük ekonomisi olan ülkeler arasında gösterilmektedir. Ancak bu büyüklük GSYİH değerlerine bu oranda yansımamaktadır. GSYİH oranlarının arttırılmasına, yönelik birtakım yapılanmalara ihtiyaç duyulmaktadır. $\mathrm{Bu}$ durum Türkiye'nin diğer gelişmiş ülkelerle rekabetinde büyük önem arz etmektedir.

2. Ar-Ge harcamalarına ayrılan payların arttırılması Türkiye için büyük bir öneme sahiptir. Özellikle teknoloji rekabetine ayak uydurabilmek, bu oranların artırılmasına bağlıdır.

3. Türkiye'de son yıllarda teknolojiye ayrılan kaynakların artırıldığı görülmüş olsa da eğitim kalitesinin çok iyi olmadığ 1 söylenebilir. Eğitimin, teknolojiyle iç içe entegre edilerek, mevcut sorunların giderilmesine çalışılmalıdır. Ayrıca konuyla ilgili olarak, bilişim teknoloji öğretmenlerinin her okulda istihdamının sağlanması önerilebilir.

4. Öğrenci başına yapılan harcamaların diğer ülkelerin oldukça gerisinde olduğu düşünüldüğünde, bu kaynakların artırılmasının altını bir kez daha çizmek gerekmektedir.

5. Bilim ve teknolojiye gerekli önemin verilmesi bir ülkeyi çağdaş kılacaktır. Patent başvuru sayılarının artırılmasında gereken tüm paydaşların işe koşulması gerekmektedir. Konuyla ilgili olarak gerekli politikaların düzenlenmesi ivedilikle gerekmektedir. Üniversitelere bu konuda büyük bir görev düşmektedir. Öğretim üyelerinin bu konuda teşvik edilmesini içeren birtakım düzenlemelere gereksinim duyulmaktadir.

6. Teknolojik gereçlere sahip olmada satın alma gücü önemli bir değişkendir. $\mathrm{Bu}$ nedenle özellikle eğitimde bu gereçlere sahip olmada birtakım düzenlemelere ihtiyaç bulunmaktadır. Bazı vergi düzenlemeleri, kamu ve özel kurumlardan özellikle eğitim kurumlarına vereceği destekler vb. girişimlerin arttırılmasına ihtiyaç duyulmaktadır.

7. İnternet günümüzün en önemli teknoloji kullanım aracıdır. İnternet erişim imkânlarının ülkelerde artırılmasının yanında, bu erişimin her mekânda ve yüksek bir hızda sağlanması günümüzde bir gereklilik halini almaktadır. Türkiye'nin de bu şartları sağlama da daha istikrarlı olmasını sağlayıcı önlemler alınmalıdır. Özellikle üniversitelerin bu bağlamda öncü olmaları gerekmektedir.

8. Araştırma ile ilgili daha geniş kapsamlı bir karşılaştırma, ülke sayılarının artışı ve yapılabilecek daha detaylı araştırmalar gelecekte yapılacak çalışmalar için önerilebilir.

\section{Kaynaklar}

Akarsu, F. (1999). Japon Ĕgitim Sistemi. Selçuk Esenbel, A. Murat Demircioğlu (Ed.), Çağdaş Japonya'ya Türkiye'den Bakışlar içinde (s. 193-210). Simurg.

Bakioğlu, A., Altay Gökmen, İ. (2013). Japonya Eğitim Sistemi. Ayşen Bakioğlu (Ed.), Karşılaştırmalı Eğitim Yönetimi (2. Baskı) içinde (s. 243-288). Nobel.

Bilişim Sanayicileri Derneği-TÜBİSAD. (2012). Atılım İçin Bilişim, Türkiye Ekonomisi İçin Bilgi ve İletişim Teknolojileri Sektörü-Atılım Stratejisi 2023. TÜBİSAD. 
Büyüköztürk, Ş., Kılıç Çakmak, E., Akgün, Ö. E., Karadeniz, Ş., Demirel, F. (2019). Bilimsel Araştırma Yöntemleri (26. Baskı). Pegem Akademi.

Cural, M., Pekkaya, M. ve Oral, İ. (2016). Yükseköğretimde Öğrenci Harcama ve Maliyetlerinin Hesaplanması: Bülent Ecevit Üniversitesi Örneği. Ekonomik ve Sosyal Araştırmalar Dergisi, 12(1), 21-44.

Çelik, V. (2012). Okul Kültürü ve Yönetimi (5. Baskı). Pegem.

Çetindamar, D., Can, Ö. ve Pala, O. "Technology Management Activities and Tools: The Practice in Turkey"', PICMET 2006, Proceedings, 9-13 Temmuz, 2006, 92-98.

Erdoğan, İ. (2003). Çağdaş Eğitim Sistemleri (5. Baskı). Sistem.

Ersoy, H. (1998). Türk ve Alman Eğitim Sistemlerinde Ortaöğretim Kurumlarının ve Müfredatlarının Karşılaştırılması, Sakarya Üniversitesi, Sosyal Bilimler Enstitüsü, Yayınlanmamış Yüksek Lisans Tezi.

Gräsel, C. (2007). The Use of Computer Tools in Implementation Projects in Schools. Research in Comparative and International Education, 2(1).

Güvenç, B. (2002). Japon Kültürü (2. Baskı). Türkiye İş Bankası Kültür Yayınları.

http://www.gtai.de/GTAI/Navigation/EN/Invest/Business-location-germany/RDframework/rd-landscape.html, Erişim Tarihi, 15.12.2019.

http://www.stat.go.jp/english/data/kagaku/1540.htm, Erişim Tarihi, 28.11.2019.

İnan, C. ve Bekler, E. (2014). PISA Sinavlarında Türkiye'nin Performansı ve Öğretmen Eğitiminde Çözüm Önerileri. Turkish Studies-International Periodical For The Languages, Literature and History of Turkish or Turkic, 9(5), 1097-1118.

ISEI. (1989). Bügünkü Japonya. Uluslararası Eğitim Enformasyon Merkezi, Tokyo: Japan Echo.

Kantos, E. Z. (2011), Federal Almanya Cumhuriyeti Eğitim Sistemi. Ali Balcı (Ed.) Karşılaştırılmalı Eğitim Sistemleri içinde (s. 49-68). Pegem Akademi.

Karsl1, M.D. (2004). Yönetsel Etkililik (2. Baskı). PegemA.

Kırankabeş, M. C. ve Erçakar, M. E. (2012). Importance of Relationship Between R\&D Personnel and Patent Applications on Economics Growth: A Panel Data Analysis. International Research Journal of Finance and Economics, 92, 72-81.

Memmedova Telci, A. (2011). Japonya Eğitim Sistemi. Ali Balcı (Ed.), Karşılaştırmalı Eğitim Sistemleri içinde (s. 365-382). Pegem Akademi.

Nakayama, M. ve Ueno, M. (2008). Current educational technology research trends in Japan. Education Tech Research Dev, 57, 271-285.

PISA 2018 Türkiye Ön Raporu, (2019). http://pisa.meb.gov.tr/wpcontent/uploads/2020/01/ PISA_2018_Turkiye_On_Raporu.pdf. Erişim Tarihi: 18.02.2020. 
Rasinen, A., Virtanen, S., Endepohls-Ulpe, M., Ikonen, P., Ebach, J. \& Stahl-von Zabern, J. (2009). Technology education for children in primary schools in Finland and Germany: different school systems, similar problems and how to overcome them. Int J Technol Des Educ. 19, 367-379.

Uşun, S. (2009). Information and Communications Technologies (ICT) in Teacher Education (ITE) Programs in The World and Turkey. Procedia Social and Behavioral Sciences, 1, 331-334.

www.oecd.org, Erişim Tarihi, 09.05.2020.

www.tuik.gov.tr, Erişim Tarihi, 09.05.2020.

www.wipo.int, Erişim Tarihi, 09.05.2020. 